\title{
Analysis of Lightning Generated Over-Voltages on Voltage Regulating Devices in Distribution System with Centralized Wind Turbine Generators
}

\author{
Raghavender D. Goud, Ramesh Rayudu, Ciaran P. Moore, Michael Emmanuel \\ School of Engineering \& Computer Science Victoria University of Wellington New Zealand \\ Email: raghu@ecs.vuw.ac.nz
}

\begin{abstract}
The effect of global warming is expected to increase the number of lightning strikes with the capacity to alter the operations of power lines and voltage regulating devices. This problem is exacerbated by the rapid proliferation of wind power generation in the distribution system, which increases the propagation of lightning strikes in the network. This paper presents the impact of lightning generated over-voltages on voltage regulating devices of the IEEE-34 feeder with utility-interactive centralized wind turbine generators (WTGs). Three deployment scenarios are considered: centralized WTG close to the feeder source, midpoint and end. Results show the occurrence of over-voltages and high fluctuations across the voltage regulators and fixed capacitors regardless of where the WTG is deployed. However, the WTG deployed closest to the feeder end resulted in higher over-voltages and fluctuations than the other two scenarios. This analysis is critical to network planners concerned about lightning protection and risk assessment.
\end{abstract}

Index Terms-Lightning, Wind Turbine Generator, Distribution System.

\section{INTRODUCTION}

Utilities around the world now have to manage the increase in interconnection requests of distributed generation (DG) integration with the distribution network. This is due to the demand for sustainable energy, deregulation of the electricity market and increased taxation of green house gas emissions [1]. However, the integration of DGs, such as wind turbine generators, into the distribution network poses new design challenges for network planners and operators.

One of the major problems to be addressed while integrating WTGs with the distribution network is lightning strikes. Wind turbines are generally tall and isolated structures in their surroundings. They are installed at locations with high thunderstorm activity to capture more energy from the wind [2]. Moreover, there is an increase in the incidence of lightning strikes due to the effects of global warming [3]. All of these factors contribute to the increased likelihood of lightning strikes to the distribution system with WTG integration.

In the event of a lightning strike, the lightning generated over voltages can propagate throughout the system. These lightning generated over-voltages, arriving through the electrical wiring in the distribution network, can damage electrical devices such as voltage regulators and capacitors in the distribution system. A major cause of electrical power system outage is due to lightning strikes on transmission and distribution systems [4].

Lightning is considered a fast front transient phenomenon, which injects over-voltages into the system due to steep rise times of the order of one to ten microseconds [5]. Therefore, the integration of WTGs to the distribution network should consider risk assessment and protection methods to overcome the problem of surge invasion due to lightning strikes.

Further, as the penetration of WTGs in the network continues to grow rapidly, there is a need to study the level of over-voltages at different nodes of the distribution system due to the lightning strikes in order to retain grid reliability [1].

Moreover, the extant literature shows few studies on the impact of lightning surges on distribution networks with WTGs. Rodriguez-Sanabria et al. [4] presented the impact of lightning strikes on network nodes and power lines without DG integration. Yasuda et al. [6] investigated the impact of lightning generated over-voltages and surge back flow on a wind turbine and wind farm. However, most studies have concentrated on the protection of wind turbines, boost transformers and the grid interactive transformers from surge over-voltages [4], [6]. There is very little research available in the literature on the impact of lightning on voltage regulating devices of distribution systems with DG installations.

This paper presents an analysis of lightning generated overvoltages on voltage regulators and capacitors of the IEEE34 distribution test feeder with WTGs integrated at different nodes. Here, three deployment scenarios of a centralized WTG are considered, they are: WTG close to the feeder source, WTG at midpoint and WTG at end. Sensitivity analysis with respect to power losses and voltage are used to site the WTG within particular node clusters [7]. The effects of lightning strikes to the WTG connected to the distribution network are analysed. The IEEE 34 distribution test feeder with WTGs is simulated using the PSCAD/EMTDC transient software to study the impact of lightning.

This study uses the IEEE-34 bus test feeder located in Arizona as a case study because of its record with high incidence of lightning strikes. Arizona experienced over 600,000 strikes per year between 1996 and 2005 [8]. Also, between 2005 and 2014, it experienced up to 24 stroke/sq $\mathrm{km} / \mathrm{year}$ stroke density [9]. 


\section{MODEL FOR ANALYSIS}

\section{A. IEEE-34 Bus Test Feeder}

The standard IEEE-34 bus test feeder is a typical $24.9 \mathrm{kV}$ radial bus feeder based in Arizona, USA shown in Fig. 1. There are two shunt capacitors to provide reactive power compensation connected at nodes 844 and 848. There are also two in-line voltage regulators deployed to control the voltage profile of the system [4]. Wind turbine generators are connected to the system at nodes 812,828 or 836 , i.e. close to the feeder source, at the mid point of the test feeder, and at the end of the test feeder, respectively.

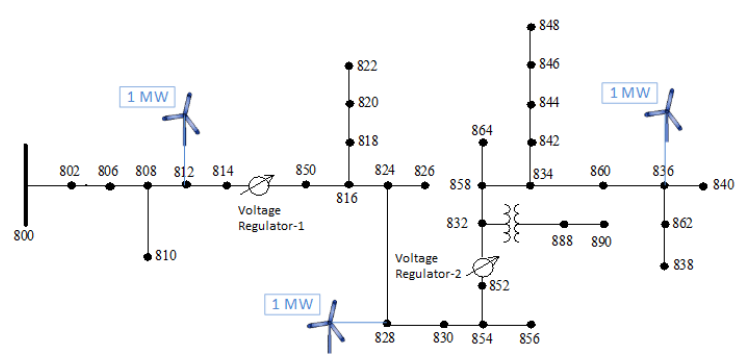

Fig. 1. IEEE-34 bus test feeder with WTG deployment.

\section{B. Wind Turbine Generator}

In this model, a $1 \mathrm{MW}$ wind turbine is connected to the distribution system via a $0.66 \mathrm{kV} / 24.9 \mathrm{kV}$ two winding transformer. The wind turbine structural components are modelled as surge impedances [6] and the interface between the phase windings and the wind turbine tower is treated as a coupling capacitance [10]. For the transient over voltage analysis, the wind turbine generator electrical components are modelled as a voltage source [4], [5], [6], [11].

\section{Transformer}

For the fast front transient studies, it is important to consider the high frequency model of the transformer (TF) [10], hence the stray capacitances are connected according to [10], as depicted in 2 .



Fig. 2. High-frequency transformer model [10].
$\mathrm{CH}$ is the capacitance between high-voltage winding to ground, CL is the capacitance of low-voltage winding to ground, and CHL is the capacitance between high-voltage and low-voltage windings. The capacitance values are obtained from a local transformer manufacturer in New Zealand [12], and are given by $\mathrm{CH}=1200 p F, \mathrm{CL}=5800 p F$, and $\mathrm{CHL}=$ $4900 \mathrm{pF}$.

\section{Metal Oxide Surge Arrester}

Medium voltage surge arresters (MVSA) and low voltage surge arresters (LVSA) are connected at the high voltage and low voltage end of the transformer to protect it from lightning surges [13]. The frequency dependent model of the surge arrester proposed by Pinceti et al. [14] is used for the simulations [15].

\section{E. Grounding System}

Grounding resistance $(\Omega)$ is modelled as a dynamic resistance, $R_{g}(\mathrm{t})$ [16]; with

$$
R_{g}(t)=\frac{R_{0}}{\sqrt{1+\frac{I(t)}{I_{g}}}}
$$

Where $R_{0}$ is the grounding resistance under normal conditions $(\Omega), I(t)$ is the lightning discharge current through the tower footing $(\mathrm{kA})$ and $I_{g}$ is the critical ionization current (kA), given by

$$
I_{g}=\frac{E_{0} \rho}{2 \pi R_{0}^{2}}
$$

$E_{0}$ is the soil ionization gradient $(\mathrm{kV} / \mathrm{m})$ and $\rho$ is the soil resistivity $(\Omega \mathrm{m})$

\section{F. Lightning Discharge Current Waveforms}

The lightning current parameters used for the simulation are first positive lightning strike according to IEC 6140024 [17] and 1.2/50 $\mu \mathrm{s}$ wave shape. There are several lightning current return stroke models available in the literature [18][19]. Most of the lightning transient simulations are based on double exponential form and Heidler function models [20]. In the widely used Heidler function, calculation of parameters is normally a complex procedure for any arbitrary values of $\mathrm{T} 1$ (front time) and T2 (time to half value). The lightning return stroke current model proposed in [20] is a two-component current waveform, which requires only simple formulae to calculate the parameters. Moreover, this waveform is in good agreement with the other standard models [18]. Hence, the two-component lightning current waveform is used for the lightning surge simulation in this work.

The return stroke current model is represented by

$$
\frac{i(t)}{I_{m}}= \begin{cases}i_{1}(t)=\left[1-\left(1-t / t_{m}\right)^{k}\right]^{n} & \text { for } \quad 0 \leq t \leq t_{m} \\ i_{2}(t)=e^{-(\tau / t) \cdot\left(t / t_{m}-1\right)^{2}} & \text { for } \quad t \geq t_{m}\end{cases}
$$

where $I_{m}$ is the peak value of the lightning current, $t$ is the time, $t_{m}$ is the time from current zero to peak, $\tau$ is the time 
constant, and $n$ and $k$ are the control parameters of current waveform shape.

$$
\begin{gathered}
t_{m}=\frac{0.8 \times T_{1}}{\sqrt[k]{1-0.1^{1 / n}}-\sqrt[k]{1-0.9^{1 / n}}} \\
t_{1}=\left(1-\sqrt[k]{\left.0.1^{1 / n}\right) \times t_{m}-0.1 * T_{1}}\right. \\
\tau=\frac{\ln 2 \times\left(t_{1}+T_{2}\right)}{\left(\frac{t_{1}+T_{2}}{t_{m}}-1\right)^{2}}
\end{gathered}
$$

where $t_{1}$ is the time to virtual origin [20], $T_{1}$ is the front time of impulse current, and $T_{2}$ is the time to half value on the tail of impulse current.

\section{Simulation Results}

In this section, the simulation results of the surge propagation and its influence on the distribution system, performed using PSCAD/EMTDC transient simulator are presented. It is assumed that the lightning strikes at the tip of WTG blades deployed at the nodes 812 and 836, and at phase B of the node 828 . In this study, two lightning current wave forms are considered: a first positive lightning strike to a WTG, which is a $10 / 350 \mu \mathrm{s}$ wave shape with a peak current of $200 \mathrm{kA}$ [17] and a lightning strike on a phase conductor with $1.2 / 50 \mu \mathrm{s}$ wave shape with a peak current of $50 \mathrm{kA}$. Lightning impulse is injected into the system at $0.1 s$ in all the cases, after the voltage profile of the system is stabilized.

\section{A. Case I: Lightning strike on WTG at node 812}

The WTG is installed with a lightning protection system (LPS) [17]. The lightning discharge current wave form for this case is $10 / 350 \mu s$. The lightning current flows through air termination and follows the down conduction path inside the blades, nacelle and tower to the ground. The surge propagation to the distribution network is through the earthing system, transformer neutral, and the transformer winding capacitances. To protect from these transferred over-voltages, the WTG transformer is protected with surge arresters at both sides.

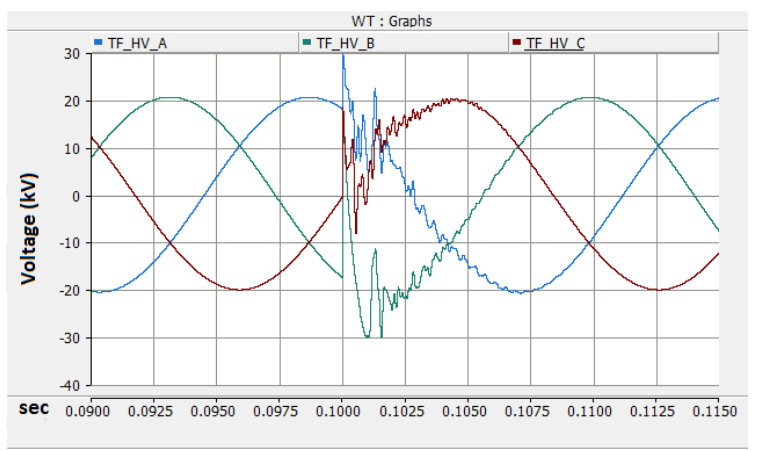

Fig. 3. Case I: Voltage across the WTG transformer HV terminals.

The surge transfer to the distribution feeder is evident from the voltage profile on the high voltage side of the WTG



Fig. 4. Case I: Voltage at the in-line voltage regulator-1.

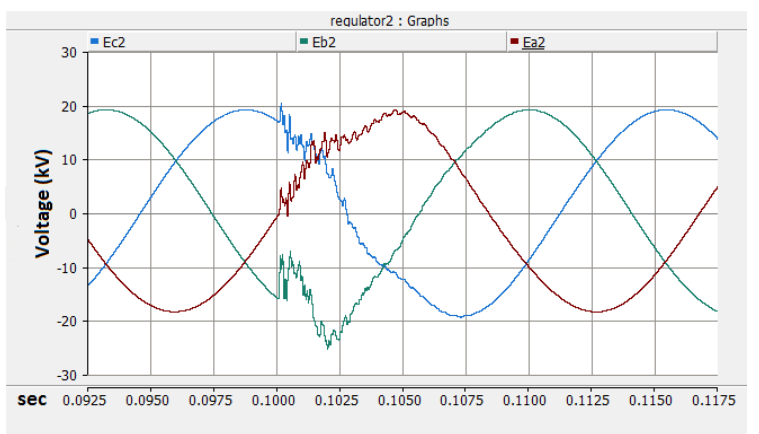

Fig. 5. Case I: Voltage at the in-line voltage regulator-2.

transformer, as depicted in Fig. 3. In this scenario, the voltages peak at $30 \mathrm{kV}, 50 \%$ above normal case, with a significant disturbance in the voltage profile. The Peak value of the voltage occurs within first $10 \mu \mathrm{s}$ of a strike, which corresponds to the rise time of the lightning waveform.

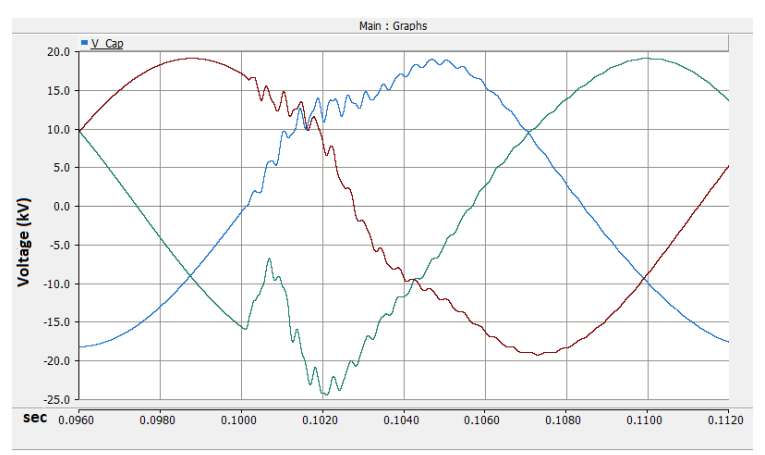

Fig. 6. Case I: Voltage across shunt capacitor-1.

Similarly, the voltage across in-line voltage regulator-1, which is close to the lightning strike point,also increases from $20 \mathrm{kV}$ peak to $30 \mathrm{kV}$, with fluctuations as illustrated in Fig. 4. The disturbances are also observed at voltage regulator-2, however, with less intensity, as shown in Fig. 5.

There are two fixed shunt capacitors in the system, located to the far end of the system at nodes 844 and 848 . The influence of lightning strikes is also present on these capacitors. Figs. 6 and 7 show the transient over-voltages and fluctuations in the voltage profile across the shunt capacitors. For both 




Fig. 7. Case I: Voltage across shunt capacitor-2.

capacitors the transient over-voltage is about $25 \mathrm{kV}$ above the base value of $19 \mathrm{kV}$.

The influence of surge over-voltage is observed immediately at the time of lightning incidence for nodes closer to the point of impact. However, for remote elements, a delay in impact about $0.2 \mathrm{~ms}$ is observed, as shown in Figs. 6 and 7.

\section{B. Case II: Lightning strike at node 828}

In this case, the WTG is deployed at the middle of the distribution network and the lightning striking point is the conductor of phase B connecting the WTG to the network. A $1.2 / 50 \mu \mathrm{s}, 50 \mathrm{kA}$ peak lightning strike is injected. There are two scenarios discussed in this case:

1) No surge arresters connected at the high voltage side of the WTG transformer: The transient over voltages without surge arresters are huge, reaching a peak of $8 \mathrm{MV}$, as shown in Fig. 8. These over-voltages travel across the network cause the same peak over-voltage at voltage regulator-1, as depicted in Fig. 9.



Fig. 8. Case II: Voltage across the WTG transformer HV terminals without surge arresters.

2) With surge arresters connected at the high voltage side of the WTG transformer: The results show that there is a decrease in the peak value of the over-voltage across the system, as illustrated in Figs. 10-14. At the TF terminals the surge arresters limit the observed over-voltage from $8 \mathrm{MV}$ to $150 \mathrm{kV}$. However, there is still a substantial disturbance of the voltage profiles at the voltage regulators, as observed in Figs. 11 and 12. In both sub cases, the surge propagation is observed throughout the network. However, installation of surge arresters reduces the magnitude of the over voltages.



Fig. 9. Case II: Voltage across the in-line voltage regulator-1, without surge arresters at the TF HV terminals.

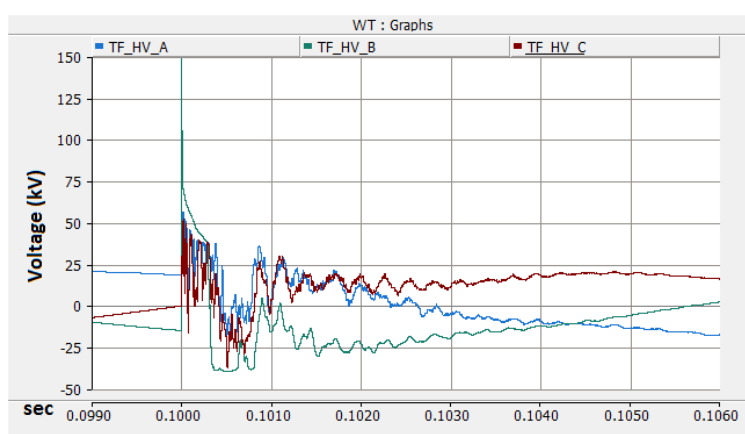

Fig. 10. Case II: Voltage across the WTG transformer HV terminals with surge arresters.

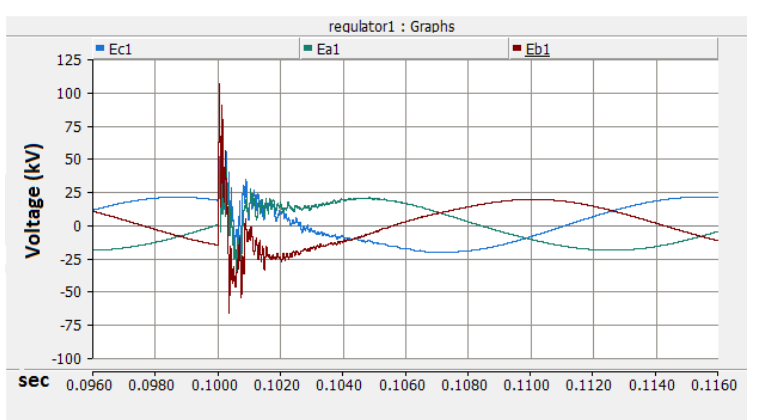

Fig. 11. Case II: Voltage across the in-line voltage regulator-1, with surge arresters at the TF HV terminals.

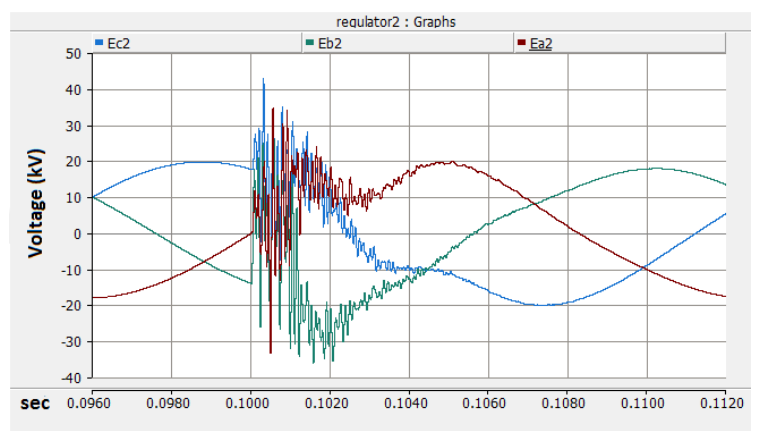

Fig. 12. Case II: Voltage across the in-line voltage regulator-2, with surge arresters at the TF HV terminals. 


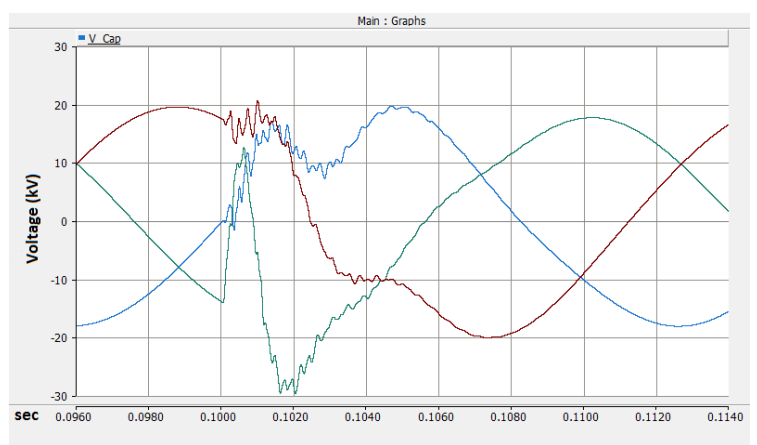

Fig. 13. Case II: Voltage across shunt capacitor-1, with surge arresters at the TF HV terminals.

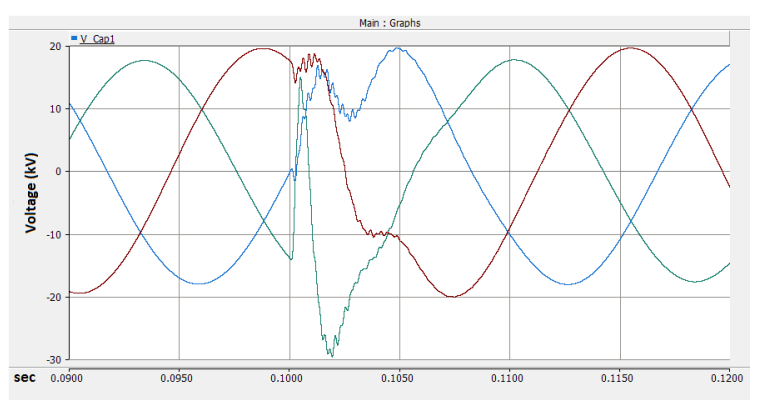

Fig. 14. Case II: Voltage across shunt capacitor-2, with surge arresters at the TF HV terminals.

\section{Case III:Lightning strike on WTG at node 836}

In the final case, the WTG is connected at node 836, which is located towards the far end of the distribution network. Again, the lightning transient impact is observed across the voltage regulators and shunt capacitors, with a peak value of about $30 \mathrm{kV}$, as shown in Figs. 15-18. However, the voltage fluctuations at the voltage regulators and shunt capacitors are larger compared to the first case.

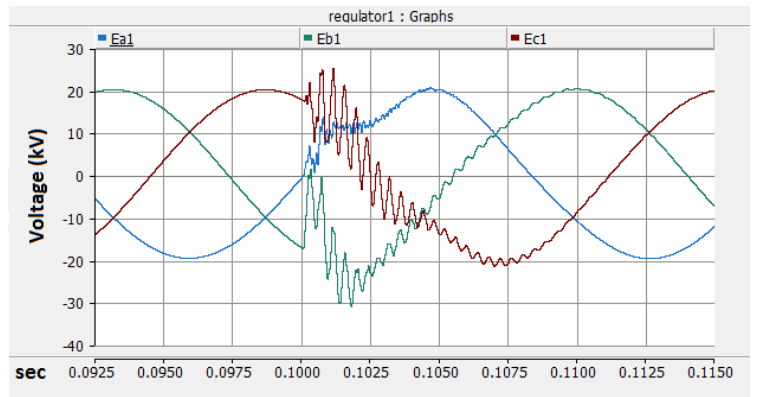

Fig. 15. Case III: Voltage across the in-line voltage regulator1.

In all cases, high transient over-voltages and fluctuations at the voltage regulators have the capacity to increase the number of tap changing operations causing early wear and tear, with higher maintenance cost. Consequently, the alteration of the operations of voltage regulators and shunt capacitors as a result

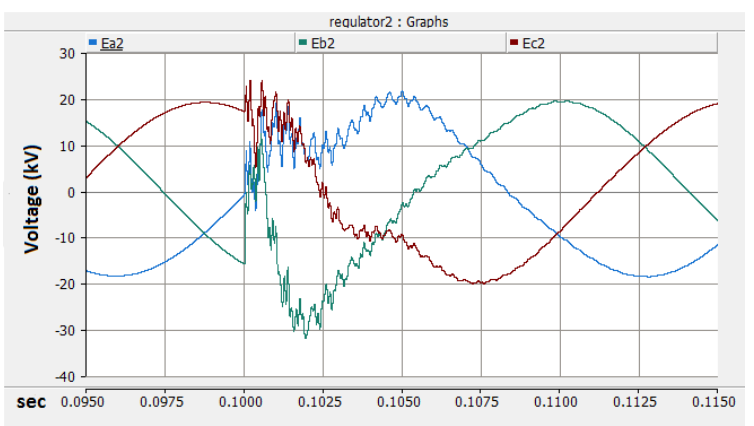

Fig. 16. Case III: Voltage across the in-line voltage regulator2 .

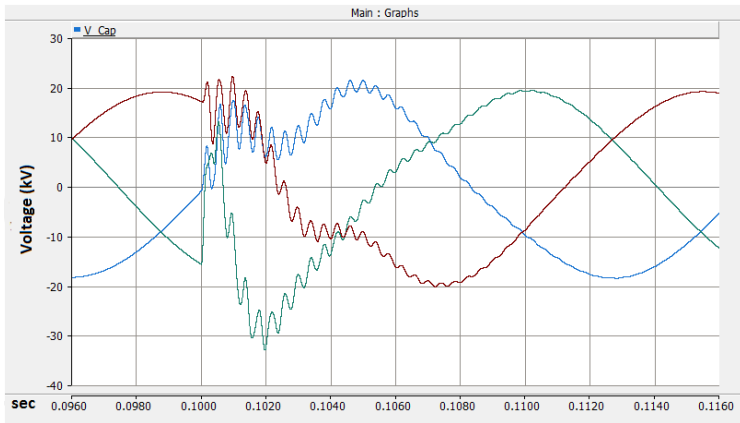

Fig. 17. Case III: Voltage across the shunt capacitor-1.

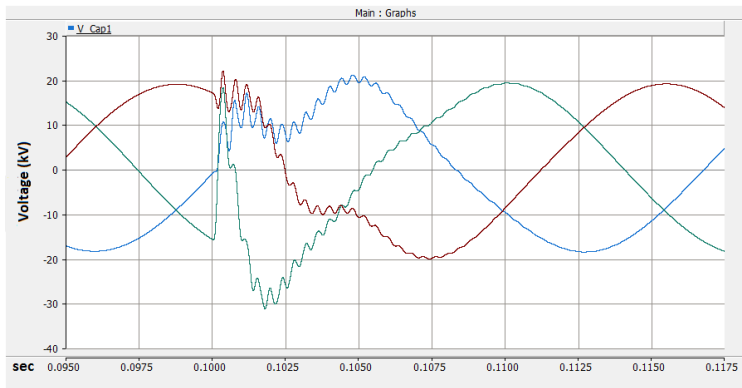

Fig. 18. Case III: Voltage across the shunt capacitor-2.

of surge propagation can lead to the violation of voltage limits with the risk of system collapse.

Although lightning surge propagation in the network is evident in all cases, there is a propagation delay observed at the distant nodes from the lightning striking point. This analysis is very important for the protection co-ordination among various protection equipment installed in the system.

\section{CONCLUSION}

Lightning surge propagation analysis is critical in planning distribution systems. The analysis carried out in this work shows that there is an over-voltage propagation across the system regardless of whether lightning strikes at the near, middle, or far end of the system. However, the over-voltages are greater for nodes closest to the lightning incident node. Furthermore, lightning strikes cause substantial over voltages 
across the voltage regulators and shunt capacitors installed in the system. It is evident from the simulation results that the transient over-voltage influence is greatest during the fast front rise times of the lightning impulse.

Acknowledgement The authors acknowledge the VUW Research Trust and thank ETEL transformers ltd. for providing the transformer characterisation data.

\section{REFERENCES}

[1] M. Emmanuel, R. Rayudu, and D. Burmester, "Impact of large-scale integration of distributed photovoltaic with the distribution network," in Power System Technology (POWERCON), 2016 IEEE International Conference on. IEEE, 2016, pp. 1-6.

[2] P. Sarajcev, "Assessment of lightning stroke incidence to modern wind turbines," in Software, Telecommunications and Computer Networks (SoftCOM), 2010 International Conference on. IEEE, 2010, pp. 97101.

[3] D. M. Romps, J. T. Seeley, D. Vollaro, and J. Molinari, "Projected increase in lightning strikes in the united states due to global warming," Science, vol. 346, no. 6211, pp. 851-854, 2014.

[4] D. Rodriguez-Sanabria, C. Ramos-Robles, and L. Orama-Exclusa, "Lightning and lightning arrester simulation in electrical power distribution systems," Electrical and Computer Engineering: University of Puerto Rico [online], 2005.

[5] N. Malcolm and R. K. Aggarwal, "The impact of multiple lightning strokes on the energy absorbed by mov surge arresters in wind farms during direct lightning strikes," Renewable Energy, vol. 83, pp. 13051314, 2015.

[6] Y. Yasuda, "Lightning surge analysis of a wind farm," in Wind Energy Conversion Systems. Springer, 2012, pp. 243-265.

[7] M. Emmanuel, R. Rayudu, and I. Welch, "Impacts of power factor control schemes in time series power flow analysis for centralized pv plant using wavelet variability model,' IEEE Transactions on Industrial Informatics, vol. PP, no. 99, pp. 1-1, 2017.

[8] Shocking facts about Arizona lightning. [Online]. Available: https:// cals.arizona.edu/backyards/sites/cals.arizona.edu.backyards/files/p16.pdf

[9] Lightning data. [Online]. Available: http://thunderstorm.vaisala.com/ explorer.html

[10] A. M. Abd-Elhady, N. A. Sabiha, and M. A. Izzularab, "High-frequency modeling of Zafarana wind farm and reduction of backflow currentovervoltages," International Transactions on Electrical Energy Systems, vol. 24, no. 4, pp. 457-476, 2014.

[11] E. A. Badran, M. E. Rizk, and M. H. Abdel-Rahman, "Analysis and suppression of back-flow lightning surges in onshore wind farms," Journal of Lightning Research, vol. 3, pp. 1-9, 2011.

[12] Etel transformers ltd. [Online]. Available: http://www.eteltransformers. co.nz/

[13] N. Malcolm and R. Aggarwal, "Analysis of transient overvoltage phenomena due to direct lightning strikes on wind turbine blade," in PES General Meeting - Conference \& Exposition, 2014 IEEE. IEEE, 2014, pp. 1-5.

[14] P. Pinceti and M. Giannettoni, "A simplified model for zinc oxide surge arresters," IEEE Transactions on Power Delivery, vol. 14, no. 2, pp 393-398, 1999.

[15] M. C. Magro, M. Giannettoni, and P. Pinceti, "Validation of ZnO surge arresters model for overvoltage studies," IEEE Transactions on Power Delivery, vol. 19, no. 4, pp. 1692-1695, 2004.

[16] J. Wu, J. He, B. Zhang, and R. Zeng, "Influence of grounding impedance model on lightning protection analysis of transmission system," Electric Power Systems Research, vol. 139, pp. 133-138, 2016.

[17] International Electrotechnical Commission, "IEC 61400-24 wind turbines-part 24: Lightning protection,” 2010.

[18] H. Heidler, "Analytische blitzstromfunktion zur lemp-berechnung," 18th ICLP, Munich, Germany, 1985, 1985.

[19] C. A. Nucci, G. Diendorfer, M. A. Uman, F. Rachidi, M. Ianoz, and C. Mazzetti, "Lightning return stroke current models with specified channel-base current: A review and comparison," Journal of Geophysical Research: Atmospheres, vol. 95, no. D12, pp. 20395-20 408, 1990.

[20] D. Rajii and M. Todorovski, "Two-component current waveform for lightning simulation," IEEE Transactions on Electromagnetic Compatibility, vol. 57, no. 5, pp. 1062-1069, Oct 2015. 